\title{
Exploring the relationship between technology and care: A qualitative study of clinical practice for nursing students
}

\author{
Kristin Jordal ${ }^{* 1}$, Kristin Heggen ${ }^{2}$, Kari Nyheim Solbrække ${ }^{2}$ \\ ${ }^{1}$ Faculty of Health Sciences, University College of Buskerud and Vestfold, Tønsberg, Norway \\ ${ }^{2}$ Institute of Health and Society, Faculty of Medicine, University of Oslo, Oslo, Norway
}

Received: October 16, 2014

DOI: $10.5430 /$ jnep.v5n2p58
Accepted: November 13, 2014 Online Published: November 24, 2014

URL: http://dx.doi.org/10.5430/jnep.v5n2p58

\begin{abstract}
Background/Objective: The aim of this study is to explore the interaction between technology and care in the student-patient relationship during clinical practice training. In the traditional discourse on nursing, technology is seen as insignificant or secondary to the actual work of caring. Using new insights from the social sciences field on how to understand technology, this paper focuses on the important, but somehow underrated, relationship between technology and the human element in clinical practice.
\end{abstract}

Methods: This article reports findings from a field study of Norwegian nursing students in hospital practice during second year training. Six women and three men participated in the study. The case-oriented analysis follows a cultural-analytical tradition in which the main objective is to investigate routines and ingrained conceptions in order to see familiar phenomenon and patterns in new ways. The main question was: How do Norwegian nursing students learn to handle technology and care in their education programme?

Results: With a socio-cultural perspective on student learning and data from participant observation, the findings of this paper show various ways in which the presence of technology influences the interaction between students and patients. The study demonstrates how technology creates challenges for students in their interactional bedside work. However, technology is also revealed as offering new opportunities for contact and care.

Conclusion: Technology and the human element are linked in complex ways in students' bedside work. This aspect of bedside care has not yet been given sufficient attention in the nursing education programme. In our view, this is a matter of concern; we conclude that nursing education needs to include updated and more nuanced perspectives that will better address this complexity.

Key Words: Nursing education, Clinical placement, Technology, Care, Socio-cultural learning

\section{Introduction}

Although the relationship between humans and technology has become increasingly important in a modern and hi-tech health service, and despite the fact that nursing has always involved various types of equipment and objects, ${ }^{[1-3]}$ the technology involved in close contact with patients has been given very limited attention in nursing education. This may be due to the fact that nursing culture, according to Barnard and Sandelowski, is characterised

\footnotetext{
*Correspondence: Kristin Jordal; Email: Kristin.Jordal@ hbv.no; Address: Faculty of Health Sciences, University College of Buskerud and Vestfold P.O. Box 2243, NO-3103 Tønsberg, Norway.
} 
by a far-reaching distinction between humans/non-humans and between touch/technology. ${ }^{[1]}$ This dichotomy has contributed to the creation of a fundamental discursive distinction between the human element and technology. A distinction of this kind can also be seen both in society in general and in the discipline of science. The predominant perception is that objects and technologies are positioned on the outside or are supplementary to human meaning making and interaction. ${ }^{[4-6]}$ This outside perspective, which implies that objects and technologies are neutral, means that although a nurse may use them, they are, nonetheless, not regarded as part of the interpersonal processes of the profession: 'Technology is conceived as mechanical means, separate to consideration of values. In fact, technology is conceived as socially, culturally and morally neutral'. ${ }^{7]}$ As we see it, this mechanical and, to some extent, limiting view of technology is also reinforced in the basic student syllabus. Here, the moral and attitudinal aspects hold a central position. Work and patient care are identified as pure person-to-person encounters between patient and nurse. ${ }^{[8-10]}$

In recent decades, new perspectives have emerged in the social sciences and the humanities on the relationship between human meaning making and technology. ${ }^{[4-6,11]}$ These perspectives inspire us when we propose that nursing is characterised to a high degree by the use of objects and technology. Going even further, we believe that good patient care must also include ways of understanding, using and involving technology. ${ }^{[6]}$ As a result of our particular interest in the way that nursing students learn their profession, ${ }^{[12,13]}$ as well as our surprise at what we regard as the oversimplified and normative narratives in the syllabus literature concerning what bedside nursing and care are and should be, we have conducted field work on students' clinical practice in the hospital environment. The participant observation focused on how the hospital department's different equipment, routines, procedures, tools and objects are specifically included in nursing students' work with patients. With a socio-cultural perspective on the students' participation in practice, ${ }^{[11]}$ the routines, equipment and tools used by the students were regarded as part of the repertoire that characterises the hospital department as a community of practice. ${ }^{[11,14]}$ The aim of the study is to explore the interaction between technology and care in the student-patient relationship during clinical practice training.

We ask the following research question: How do Norwegian nursing students learn to handle technology and care in their programme of education?

Although the structure of nursing education programmes can vary greatly between different countries, making comparisons challenging, ${ }^{[15]}$ we still suggest that the ability to care combined with practical nursing skills involving the tools of the trade are at the core of nursing education across the world. ${ }^{[2,16]}$ A number of international research papers report on both the importance as well as the challenges re- lated to the training of students in clinical placements. ${ }^{[17-19]}$

\section{Theoretical framework}

A key theoretical starting point for our study is Wenger's perspective on learning, ${ }^{[11]}$ which is broadly understood as the individual's meaning-making processes in life's many communities of practice. In certain periods of life- for example, when taking a bachelor's degree in nursing these learning processes are intensified in a formal qualification cycle. ${ }^{[14]}$ In line with this perspective, student learning is linked to constantly ongoing processes in which the student's experience of meaning, identity, community and practice constitutes a pivotal point. The learning processes are thus primarily associated with the extent to which the students perceive their experiences and their commitment in the community of practice as meaningful. Student learning in clinical practice is also linked to three different dimensions of the community of practice. The first dimension concerns developing and negotiating an understanding of the purpose of the activities and thus being able to make efforts to achieve overall objectives. The second dimension centres on the development of different forms of commitment by understanding and developing appropriate relationships and forms of collaboration according to which parties work together and how. The final dimension to which the learning processes is linked, and the one which we particularly emphasise in this article, is the joint repertoire of the community of practice in which the students are to understand and negotiate meaning when using its tools and equipment and when following its routines and discursive practice. ${ }^{[1]}$

\section{Mediating artefacts}

Mediating artefacts form another basic concept in the sociocultural learning perspective. The concept demonstrates how man-made objects, tools, routines, methods, procedures and discourses are included in the repertoire of the community of practice and are thus perceived as carriers of the culture in which they have been created. ${ }^{[14]}$ In a hospital department, such artefacts can, for example, include hypodermic syringes, blood sugar measuring equipment, the bed pan, patient records, a procedure for dressing wounds, an interview handbook, an anti-infection regime or the agenda for the day. According to Nygren, the fact that the artefacts mediate means that:

... they link the persons together so that the actual artefact simultaneously affects the way the persons are socially linked. The artefact thus comes 'in-between' in a manner that affects the relationships. The local cultural artefacts thus also mediate the relationships between practitioners and their users [author's translation]. ${ }^{[14]}$

In contrast to a traditional discourse on nursing, in which technology is positioned as insignificant or as secondary to 
the actual work of caring, ${ }^{[7]}$ socio-cultural perspectives argue that objects and technologies are interwoven with and inextricably linked to the interpersonal and social processes that take place in a hospital department. Put differently, in this setting, they not only influence the interaction between colleagues but are also included in and affect the students' interaction with the patients. ${ }^{[14]}$

\section{Methods}

This article forms part of a qualitative $\mathrm{PhD}$ study of nine students undergoing the bachelor's degree programme in nursing and is based on material from the students' practice period at the hospital in the second year of their training. Six women and three men participated in the study. The first author carried out 100 hours of participant observation in the surgical and medical departments where the students had been allocated practice places. The students enrolled voluntarily after reading information on the study advertised on the in-house website of the university college. The students were given information on the framework and purpose of the study and were told that they could retract their participation at any time, and that the first author's participation in their practice was not part of the evaluation of the university college.

The research design of participant observation provides the opportunity to describe what students do in a natural institutional learning context that simultaneously includes objects and things understood as the material artefacts of the field. This is an area that has not been given sufficient attention in field work but which is, nonetheless, highly significant — 'the ethnography of everyday life'. ${ }^{[20]}$ Once formal access to the field had been secured, it was the students' ultimate practice place allocation that decided where the actual field work was to be conducted. The students' practice period consists of ten weeks in the medical department and ten weeks in the surgical department. The first author aimed to observe the students both at the beginning and at the end of this period. However, it was the students themselves who chose the days they wanted to have the first author accompany them. This was largely on day shifts. The first author accompanied the students from the end of the morning reporting session up to the afternoon change of shift. This demonstrates the way in which a researcher's access and participation in the field can be affected by practical challenges, adaptation and negotiation. ${ }^{[20]}$

Each student was monitored for between 10 and 15 hours during the period. The students had been given prior instruction on the fundamental nursing procedures in the laboratory department of the university college. These skills were now to be performed in practice in actual patient situations and in line with each department's organisation and routines. Exactly which patients and how many tasks the students were responsible for regarding each patient changed throughout the practice period. At the beginning, they accompanied and assisted their practice supervisor after which they were gradually given more freedom of action. The material on which this article is based has been drawn from observations made once the students were allowed to work more independently.

\subsection{Participant observation}

The observation sequences were organised based on the wish to increase the understanding of what student bedside work actually entails. In line with the study's practiceoriented perception of learning and its broad understanding of technology, the observation was directed towards the students' use of specific physical apparatus and medical technology equipment as well as their handling of daily routines, admission and discharge procedures, and antiinfection regimes. The field notes were written during the observation sessions and were then reviewed and further developed on completion of the day in the field. The notes consisted of descriptions of selected situations the students had experienced as well as the methodological and analytical reflections made by the first author during the process. These reflections could concern her role as a researcher or could be the start of the interpretation of what had been observed and written down. The methodological field work and the subsequent analyses are therefore not to be understood as separate stages but should be viewed in conjunction with each other. ${ }^{[20,21]}$

\subsection{Establishing trustworthiness}

The concept of trustworthiness in qualitative research can be addressed in several ways. ${ }^{[22]}$ In a social constructivism perspective, field work is characterised by cooperation between the researcher and the participants, where the truth is co-constructed and based on multiple realities. ${ }^{[20,22]}$ Hence, the first author systematically involved each student in a reflection session at the end of the day. The field notes, with their initial understandings and interpretations of the actual situations, represented an important contribution to these discussions. When the field work was finished, the three authors of this paper worked both individually and together to analyse the material. The first author also presented and discussed the preliminary analysis with other teachers and research fellows without any connection to the study. ${ }^{[22]}$

\subsection{Ethical considerations and the role of the re- searcher}

An application for the study was accepted by the Regional Committee for Medical and Health Research Ethics. Participant observation in fully operational hospital departments can be challenging since it includes patients who are clearly in vulnerable situations. The nurse in charge, therefore, acquired verbal consent from the patients who were involved. If he or she was positive, the first author introduced her- 
self and gave the patient a leaflet describing the study. The leaflet contained contact information that could be used if the patient wanted more information or regretted giving his/her consent. The first author wore a white uniform with the university college logo and had a name tag with Researcher/Research Fellow as her title. To avoid receiving information on all the department's patients, the first author arrived at the department after the morning reporting had finished and the work had been allocated. She was then given a short introduction to the student's patients for that shift.

The first author, who is herself a trained nurse and works as an assistant professor at the university college, had to assess how observant or participative she could and should be at any given time. In practice, she played a combination of these research roles. ${ }^{[20,23]}$ The roles had to counterbalance each other to avoid inflicting unnecessary strain on the patients while at the same time allowing the researcher to observe the students and to see how they found solutions to the situation. Examples of situations in which the first author chose to participate were if a patient was at risk of falling or if the first author was directly asked for advice or help. When the students asked questions at other times, the first author encouraged them to do what they would have done if they had been alone. The field work was thus a delicate balance between observation and participation. It also required a continuous and heightened awareness of the relationship between the roles of teacher, nurse and researcher. ${ }^{[23]}$

\subsection{Situation analysis}

Nursing education takes place in two main learning arenas: at the university college and during clinical studies. An explicit aim in every training programme is to find various ways of combining theoretical and practical knowledge. One way of inspiring students to become aware of the close relationship between theory and practice is the text books' use of exemplary cases or real life stories. ${ }^{[16]}$ In this paper, we use a typical situation taken from a standard text book ${ }^{[10]}$ and one student's narrative description of a significant experience to inspire and sensitise the analysis to the underlying values in the nursing culture and educational programme. The student was a participant in our study and the narrative extract is from the daily reflection session the first author conducted with students during the participant observation phase. The extract from the student syllabus was taken from the standard text books on basic nursing skills, Grunnleggende sykepleie, ${ }^{[10]}$ which are used by students in the majority of nursing education programmes in Norway throughout their training.

\section{Just an ordinary day}

In the opening chapter on general nursing, the authors aim to give students their first insight into what nursing is by using a patient narrative on 'just an ordinary day'. ${ }^{[24]}$ The Published by Sciedu Press narrative concerns an elderly woman, who is lying in bed and reflecting on her personal experiences as a patient. She is particularly concerned about how the nurses carry out her personal care routine. A nurse called Amund is said to have good hands and takes his time, whereas Siv displays a wise and questioning gaze - a gaze that enables the female patient to think that 'she knows what it's like for me'. The narrative seems to work as a starting point for bringing together key features of the profession. A recurring subject in the chapter is how nurses' actions must always be firmly rooted in their attitudes and in the basic values of the profession. This is formulated more precisely as: "What we nurses do cannot be separated from how we do it, i.e. the manner in which we carry out our nursing actions' [author's translation]. The importance of this statement is emphasised in the text book by the use of italics, pink marking and a large exclamation mark. This affirmation of the way in which nursing values and attitudes are interlinked in work with patients is repeated several times in the chapter: "A firm but understanding gaze and a clear and calm voice can convey thoughtfulness, which for the patient represents an opening out to the world and to the coming day.' [author's translation] (p. 20)

It also seems that nursing students are to learn a way of behaving that reflects their values and attitudes in the form of body language. This specific way of behaving is to characterise their role as carers. As we see it, the moral state of the individual and the physical aspects of person-to-person nursing dominate the introductory chapter on basic nursing skills. At the end of the chapter, the relationship between pure person-to-person care, on the one hand, and the health service's technological aids, on the other, is described in the following terms:

In the modern health service we have a number of technological aids that are important and necessary when we are to observe a patient's condition. Nonetheless, the most important object is the nurse's hands and her senses of sight and hearing .... the care and consideration we can convey by the pressure of a hand, an arm round the shoulder or a hand on a feverish forehead [is] often probably just as important for the patient as the most highly developed aids and medicines' [author's translation]. ${ }^{\text {[24] }}$

To us, this paragraph demonstrates very clearly the discursive distinction and hierarchical division between humans/non-humans and technology/touch, which is so characteristic of the profession and its knowledge base. The human aspects of the profession are often described as essential for student motivation and the choice of nursing as a future career. ${ }^{[9]}$ However, a full understanding of what nursing care entails gives rise to significant challenges for students. ${ }^{[25]}$ This is clearly demonstrated in the reflection 
discussion the first author had with one of the youngest participants in the study. She describes people's reaction to the fact that she has taken up nursing as follows:

They pat you a bit extra on the back and say 'Then you must be really caring'-do you get what I'm trying to say? I just think that the conception of nursing in a way as just a caring profession is wrong. The question then is 'What is care?' So right now I feel that the nursing role is very vague. I hope I'll have a good practice period and that things fall into place. You know, I'm not really sure what role I have because I feel I've made a big mistake if nursing is sort of only care. Do you understand what I mean?

We have used the first chapter of the textbook and the above passage from one of the students to offer a situation analysis before further qualitative data analysis. The analysis process is described in more detail below.

\subsection{Analysis}

According to Hammersley and Atkinson, qualitative data represent 'materials to think with'; ${ }^{[20]}$ analytical work is thus characterised by a reflective alternation between the empirical material, the theoretical perspectives and the analytical working methods that the study employs. However, the specific way in which this is conducted in qualitative studies will vary considerably. ${ }^{[23]}$ In this article, we are inspired by a cultural-analytical working method ${ }^{[21,26]}$ and, in line with this analytical approach, the field notes were transcribed before these descriptions of everyday life were investigated. Analytical work involves selection and interpretation $^{[20]}$ as well as comparison and contextualisation. ${ }^{[26,27]}$ In this study, we began by reading the entire observation material before selecting parts of it on the basis of an understanding of its relevance to the study's main focus.

The actual analytical work took shape while we read and discussed the material, constantly on the search for answers to several questions, for example: How do the students use technology? How do they handle technology in relation to the patient? How do the students relate to the patient when technical aids are involved in the situation? How do the students talk about the technology in different patient situations? Are there similarities and differences depending on the type of technology? How did the student talk about technological equipment in relation to the patients' responses?

Through a careful and repeated reading of the material, we identified sentences and paragraphs that gave tentative answers to these questions. Then we took a more theoretical standpoint using the socio-cultural concept of 'mediating artefacts' and Wenger's understanding of student learning as a negotiating and meaning-making process in the community of practice. ${ }^{[11]}$ These perspectives, used as optical lenses in the subsequent analytical work, gave us an opportunity to elaborate the material through a collaborative writing process that characterises the cultural-analytical working method. ${ }^{[21,26]}$ Gradually we elaborated and established three themes: 1) the presence of technology in the students' interactions with the patients; 2) technology as a challenge in the interactional work; and 3) technology as an opportunity for contact and care. The analysis was centred on two cases, which were chosen because they optimised insights into our research question. ${ }^{[28]}$

In a cultural-analytical tradition, the main objective is to investigate routines and ingrained conceptions - to see familiar things in new ways. ${ }^{[21,26]}$ Wenger's socio-cultural learning perspective ${ }^{[11]}$ made it possible for us to use new approaches and interpretations of bedside nursing since the students' participation in the practice can be analysed as cultural learning processes. At the same time, Wenger's concept of repertoire addresses the community of practice's materiality consequently, we also decided to 'follow the objects' in the students' daily work. To sum up; The community of practice in which the students participated is understood as part of a wider nursing culture in which specific conceptions, values and ways of behaving are assigned special importance. ${ }^{[26,27]}$ These theoretical perspectives thus provide us with the opportunity to ask new questions and to turn round, or contrast, predominant understandings of bedside nursing and care in the basic syllabus. The selected cases are not particularly dramatic and could have taken place on any duty shift. In other words, they are everyday events from nursing student practice. The analytical goal of this case-oriented analysis is to make visible and describe the cultural learning processes that 'lie embedded in everyday trivialities, and are neither particularly eye-catching nor loud.' [author's translation] ${ }^{[21]}$

\section{Findings}

As will be demonstrated, student participation in the department includes being allowed access to and being part of the culturally-created artefacts ${ }^{[29]}$ that exist in the community of practice. ${ }^{[11]}$ These artefacts form part of the department's common repertoire and consist of particular words and expressions, ways of doing things, equipment and departmental routines - a mixture of activities, relational aspects and involved objects. $^{[11]}$

\section{Case 1}

Grethe is carrying out her practice in the medical department. Today, she is responsible for an elderly woman who has pneumonia. As we start the day, after the morning reporting session, Grethe tells me that she is to 'go in and take her oxygen saturation', that is, she is to measure the oxygen 
level in the elderly woman's blood. Grethe greets the patient and puts a clip, the device's sensor part, on the woman's finger. At the same time, Grethe asks:

'How's your breathing?' 'It's a bit heavy now in the morning. It seems like quite a lot has settled in my lungs during the night,' the patient replies. 'Yes, that corresponds with your saturation. It's lower now than it is in the middle of the day,' says Grethe. 'Corresponds with...?' the patient asks with a questioning look. Grethe replies 'The oxygen level of your blood is better during the day and in the evening than it is in the morning - so it's right that it's a bit heavy now.'

\section{Case 2}

John is responsible for a man in his seventies. On the afternoon I am to accompany this student, there is a suspicion that the patient has been infected by a norovirus. John, therefore, has to wear a protective gown, a facemask and gloves. When we go into the patient's room, he closely resembles a luminous warning triangle in his yellow protective equipment. John is to take the patient's blood pressure. The patient, sitting on the edge of the bed, stretches his arm out and together they try to push up his somewhat tight shirt sleeve. John sighs, straightens up and says: 'It gets pretty hot in this moon suit'.

The anti-infection measures are very conspicuous and, together with the facemask and gloves, the yellow gown is a sign that special precautions have been taken with the patient on this particular day. John is therefore addressing the obvious, but he gives it an unexpectedly humorous tone and context by calling the protective gown a moon suit. The patient asks: 'Do you have to wear it because of me?'

'It's for you and for all the others,' says John.

John then gets the blood-pressure sleeve and puts it on the patient's upper arm. When the measurement has been taken, he straightens up and throws off the yellow protective gown. The equipment and rubbish are packed together in a plastic bag that is tied. During the day, this becomes a running joke between the patient and John in which they count together how many sets of protective equipment John has had to change into. A little later, we enter the room again:

'Hello,' says the man in the bed in a rather affected American style and with a twinkle in his eye.

'Hello, here I come, ready for Easter,' says John looking down at the yellow protective gown. There is an easy, friendly atmosphere between them.

'Yes. Now you look just great,' says the patient.

\subsection{The presence of technology in the students' in- teractions with the patients}

John's yellow protective gown, facemask and gloves have specific meanings in the community of practice, meanings

Published by Sciedu Press that are based on and convey knowledge of the infectious norovirus, the danger of infection that it involves, and the department's procedures for avoiding the spread of infection. The students have to learn these specific meanings and put them into use during the practice period. When Grethe says that she is to 'go in and take her oxygen saturation', the short sentence has become meaningful for Grethe because her basic understanding of the body's anatomy and physiology is in correlation with her knowledge of pneumonia. She also knows the procedure for measuring oxygen and has practice experience, which means that she can find and handle the oxygen-measuring device. According to Wenger, ${ }^{[11]}$ this device thus embodies a chain of interwoven meanings; in a way, it becomes a physical concretisation of the joint learning history of Grethe and the community of practice that are linked to these circumstances. This represents an accepted norm that patients are in general excluded from and thereby represents a challenge for the student's bedside work.

\subsection{Technology as a challenge in the interactional work}

As we have seen, the devices used by the students include interwoven meanings that represent an accepted norm in the communities of practice. Patients, on the other hand are not familiar with these interpretations, a fact that creates challenges in bedside work. This challenge becomes apparent when Grethe is using the oxygen-measuring device to find out how much oxygen there is in the woman's blood. The percentage of oxygen saturation is shown as a figure on the device's small display panel. At the same time as reading the data, Grethe must also communicate with the patient and care for her as well as possible. Importantly, Grethe uses the community of practice's terminology, including terms such as saturation and oxygen level, whereas the woman in the bed describes her experience and feelings about her breath as being heavy and says that 'quite a lot has settled in my lungs'. As we see it, the conversation with the elderly woman display a significant difference between what is expressed from the patient's experience and point of view, on the one hand, and Grethe's use of terms that refer to what the oxygen-measuring device actually shows, on the other. Of course, through her participation in the community of practice, Grethe has a professional understanding of what the oxygen device shows. Nonetheless, since the inherent meanings that the device mediates do not generate any recognition of meaning for the patient, it appears that the device creates a challenge for Grethe's bedside work. Grethe is in a specific situation, close to the patient, when these meanings are initiated; however, as the case demonstrates, she struggles to create a connection between the meanings inherent in the actual device and the patient's expression of her physical experience. According to Barnard, the ability to influence the integration of technology and human experience is a distinctive feature of the nursing role: ${ }^{[7,30]}$ 
...nurses are positioned at an axis point between technology, individuals, clinical environments and communities and have responsibility to take a primary role in interpreting and influencing the relationship(s) between technology, health care praxis and human experience. ${ }^{[30]}$

The situation is thus marked by a demand for simultaneous interpretation and translation related to the meanings of the technology, on the one hand, and the patient's experience and interpretations of what her body is struggling with, on the other. This creates challenges for Grethe's bedside nursing on that day.

\subsection{Technology as an opportunity for contact and care}

Although students might experience the use of technological devices as a challenge in their bedside work, the opposite is also a possibility when technology opens the door for productive interaction with patients. These opportunities become apparent when John challenges the meanings that the gown has been assigned by the community of practice and lifts it out of the standard connotations. As we see it, this metaphorical manoeuvre invites the patient to talk about the anti-infection measures. In other words, the introduction of the moon suit idea provides an opportunity to talk and a manner of talking since the humorous description appears to ease the potentially difficult topic. John's use of humour and the game with the yellow protective gown influences his interaction with the elderly man and appears to create new points of contact. What at first glance looks like a humorous and defensive manoeuvre to avoid a hurtful and difficult situation can on closer consideration be understood as an active move in bedside care, far more liberating than perhaps understood. John is actively challenging the perceptions of the protective gown and the norovirus routines advocated by the community of practice and, by introducing the moon suit metaphor, makes a space for himself and the patient to create joint interpretations of the gown. John thereby renegotiates the established meanings of the artefact in the community of practice. In Wenger's framework, this is to be interpreted as 'a renegotiable history of usage':

The fact that actions and artefacts have recognisable history of interpretation is not exclusively, or even primarily, a constraint on possible meanings, but also a resource to be used in the productions of new meanings. The spontaneous creation of metaphors is a perfect example of the kind of resource provided by a renegotiable history of usage. ${ }^{[11]}$

Through his humorous interpretation of what a gown is, John is slightly bending the rules; ${ }^{[12]}$ thus, active meaningmaking work is taking place in which John renegotiates the meanings inherent in the department's repertoire. In this way, he both creates and utilises a new potential for care when working close to the patient.

\section{Discussion}

Nursing is a culture in which particular concepts of care, values and ways of behaving are assigned importance. They, therefore, affect the understanding of what is perceived as good and correct professional practice. ${ }^{[8,9,31,32]}$ In this article, we have used the narrative "Just an ordinary day" from the student text book to highlight the extent to which the nursing programme promotes and reinforces the understanding that good care and nursing in close contact with the patient are best performed in pure person-to-person encounters between the nurse and the patient. ${ }^{[24]}$ Nonetheless, the field work in this study shows that bedside nursing is largely organised around nursing tasks that include different types of objects and technology. This procedural and task-oriented focus means that close contact with the patient can seldom be purely person-to-person in nature. On the contrary, student practice at the hospital is characterised by complex links between the human element and technology, which we understand as a continuously open and man- made negotiation on what meanings should or might be brought to the fore during the health care praxis.

First, we have outlined that an ordinary day in the students' clinical practice is characterised by the fact that the department's repertoire - in the form of words and expressions, ways of doing things, equipment and departmental routines - not only forms part of the active and relational meaningmaking work between the students and the patients, but also affects this work and gives it dynamics. This is challenging because the student must carry out demanding translation and interpretation work between technology's mediated meanings and the patient's experience. At the same time, it transpires that the profession's technologies can function as a key to unlock a relational space for opportunities that have considerable potential for care. Objects and technologies are thus included in far-reaching ways in student meaningmaking processes when carrying out nursing tasks close to the patient.

Secondly, the cases from our study show how their use of the department's objects and technologies makes students move within and outside the practice location's learning history to interpret artefacts. When Grethe describes and uses the oxygen-measuring device as expected in her encounter with the elderly woman with pneumonia, this demonstrates a way of reproducing the cultural meanings of technology held by the community of practice. In other words, by interacting with technology in line with the practice community's accepted norm, both this norm and the actors involved remain carriers of the culture in which they are created. According to Henderson et al., an adaptation of this kind can 
be described as learning the rules, fitting in and not rocking the boat, a strategy the students use to become accepted in the community of practice. ${ }^{[17]}$ Nevertheless, John's bedside nursing clearly demonstrates that the repertoire of the community of practice is a potential resource for renegotiation and innovation because the students, as newcomers in the community, according to Wenger: '.. p produce meanings that extend, redirect, dismiss, reinterpret, modify or confirm - in a word, negotiate anew the histories of meanings of which they are part' [11] In this way, the students' relationship to objects and technologies also includes a meaning negotiation on the community of practice's interpretation of artefacts and learning history.

On a more general level, the students' relationship to technology in bedside nursing and care may be understood as a negotiation of meaning related to prevailing professional discourses. The students are positioned in the area of tension between how patient care and technology are talked about in the more idealised and normative academic culture and how patient care as an activity can be performed in what is described as more task- and skill-oriented communities of practice. ${ }^{[17,33]}$ The students' challenges regarding professional culture and perceptions of care are summarised as follows by Ousey and Johnson: 'Students have many obstacles to overcome during their training and education period to reach their ultimate aim of becoming a qualified nurse. Caring and culture are two of the major issues they have to understand to achieve this aim'. ${ }^{[33]}$

\section{Conclusion}

In this study, we find that student practice involves challenging situations in close contact with patients where technology and the human element are linked in complex ways. This represents aspects of bedside care that have not been given sufficient attention in the student syllabus. In our view, this is a matter of concern on several counts.

First, we are concerned because the interpersonal aspects of practicing the profession constitute a feature of nursing that still motivates young people to choose nursing as a profession. ${ }^{[9,34,35]}$ Thus, when the basic syllabus literature uses outdated and oversimplified narratives on nursing and care in close contact with the patient to convey what nursing is, the programme is at risk of not recognising the potential for identifying with the profession and the role of nurse what such a relational interest actually makes possible.

Secondly, these oversimplified perceptions of care contribute to the fact that no allowance is made in the syllabus for the complexity that students actually encounter in their clinical practice. We view this as problematic since clinical practice is a learning arena that is particularly meaningful for student learning and for the development of a professional role. ${ }^{[17,19,33,36]}$ The educational programme is in danger of losing an opportunity to empower and prepare students to handle the complex relationship between technology and care in their bedside work. This is a highlyrequired skill today as there is increasing standardisation of treatment and care and an extended use of technological aids and equipment in modern clinics.

We are, therefore, strongly of the opinion that nursing education needs updated and more nuanced narratives of care that are based on experience - narratives that not only include but also demonstrate the challenges and opportunities for good care that are actually inherent in the profession's objects and technologies.

\section{Conflicts of Interest Disclosure}

The author declares that there is no conflict of interest statement.

\section{References}

[1] Barnard A, Sandelowski M. Technology and humane nursing care: (ir)reconcilable or invented difference? Journal of Advanced Nursing. 2001; 34(3): 367-75. PMID:11328442 http://dx.doi.org $/ 10.1046 / j .1365-2648.2001 .01768 . x$

[2] Sandelowski M. Tools of the Trade: Analyzing Technology as Object in Nursing. Research and Theory for Nursing Practice. 1996; 10(1): 5-16.

[3] Sandelowski M. Devices \& desires: gender, technology, and American nursing. Chapel Hill, NC: University of North Carolina Press; 2000. 295

[4] Latour B. Reassembling the social: an introduction to actornetwork-theory. Oxford: Oxford University Press; 2005. 30.

[5] Latour B, Woolgar S. Laboratory life: the construction of scientific facts. Princeton, N.J.: Princeton University Press; 1986. 294.

[6] Mol A. The logic of care: health and the problem of patient choice. London: Routledge; 2008. 129.
[7] Barnard A. A critical review of the belief that technology is a neutral object and nurses are its master. Journal of Advanced Nursing. 1997; 26(1): 126-31. http://dx.doi.org/10.1046/j.1365-2 648.1997.1997026126.x

[8] Hem MH. Mature care: an empirical study of interaction between psychotic patients and psychiatric nurses [Doctoral dissertation]. Oslo: University of Oslo; 2008.

[9] Tveit B. Ny ungdom i gammelt yrke: en studie av sykepleierstudenters motivasjon og fagidentitet i møte med en tradisjonstung utdanning [Doctoral dissertation]. Oslo: Oslo and Akershus University College of Applied Sciences; 2008.

[10] Kristoffersen NJ, Nortvedt F, Skaug E-A, editors. Grunnleggende sykepleie Oslo: Gyldendal akademisk; 2011.

[11] Wenger E. Communities of practice: learning, meaning, and identity. Cambridge: Cambridge University Press; 1998. 318. http: //dx.doi.org/10.1017/CB09780511803932

[12] Solbrække KN, Solvoll B-A, Heggen KM. Reframing the field of gender and nursing education. Gender and Education. 2013: 1-14. 
[13] Jordal K. "Jeg vil bli en forbaska god sykepleier": to menns fortellinger om sykepleie som profesjonsvalg. In: Leseth A, Solbrække KN, editors. Profesjon, kjønn og etnisitet. Oslo: Cappelen akademisk; 2011. 57-70.

[14] Nygren P. Handlingskompetanse: om profesjonelle personer. Oslo: Gyldendal akademisk; 2004. 386 p.

[15] Salminen L, Stolt M, Saarikoski M, Suikkala A, Vaartio H, Leino-Kilpi H. Future challenges for nursing education - A European perspective. Nurse Education Today. 2010; 30(3): 2338. PMID:20005606 http://dx.doi.org/10.1016/j.nedt. 20 09.11 .004

[16] Benner P. Educating nurses: a call for radical transformation. San Francisco, CA: Jossey-Bass; 2010.

[17] Henderson A, Cooke M, Creedy DK, Walker R. Nursing students' perceptions of learning in practice environments: A review. Nurse Education Today. 2012; 32(3): 299-302. PMID:21514982 http: //dx.doi.org/10.1016/j.nedt.2011.03.010

[18] Thomas J, Jack BA, Jinks AM. Resilience to care: a systematic review and meta-synthesis of the qualitative literature concerning the experiences of student nurses in adult hospital settings in the UK. Nurse Education Today. 2012; 32(6): 657-64. PMID:22014589 http://dx.doi.org/10.1016/j.nedt.2011.09.005

[19] Vågan A, Erichsen T, Larsen K. Sykepleierstudenters syn på kunnskap og læring. Sykepleien Forskning. 2014; 9(2): 170-81. http://dx.doi.org/10.4220/sykepleienf . 2014.0087

[20] Hammersley M, Atkinson P. Ethnography: principles in practice. London: Routledge; 2007. 275.

[21] Ehn B, Löfgren O. Kulturanalyser. Malmö: Gleerups; 2002. 180.

[22] Creswell JW. Qualitative inquiry \& research design: choosing among five approaches. Los Angeles, CA: Sage; 2013. 448. PMID:24179799

[23] Patton MQ. Qualitative research \& evaluation methods. Thousand Oaks, CA: Sage Publications; 2002. 598.

[24] Kristoffersen NJ, Nortvedt F, Skaug E-A. Om sykepleie. In: Kristoffersen NJ, Nortvedt F, Skaug E-A, editors. Grunnleggende sykepleie. Oslo: Gyldendal akademisk; 2011. 15-28.
[25] Rognstad M-K, Nortvedt P, Aasland O. Helping motives in late modern society: values and attitudes among nursing students. Nursing Ethics. 2004; 11(3): 227-39. PMID:15176637 http://dx.doi.o rg/10.1191/0969733004ne691oa

[26] Ehn B, Löfgren O. Kulturanalytiska verktyg. Malmö: Gleerups; 2012. 169.

[27] Leseth AB, Solbrække KN. Profesjon, kjønn og etnisitet. In: Leseth AB, Solbrække KN, editors. Profesjon, kjønn og etnisitet. Oslo: Cappelen akademisk; 2011. 13-28.

[28] Stake RE. Qualitative Case Studies. In: Denzin NK, Lincoln YS, editors. The Sage handbook of qualitative research. Thousand Oaks, CA: Sage; 2005. 443-66.

[29] Blåka G, Filstad C. Læring i helseorganisasjoner. Oslo: Cappelen; 2007. 158.

[30] Barnard A. Philosophy of technology and nursing. Nursing Philosophy. 2002; 3(1): 15-26. http://dx.doi.org/10.1046/j.146 6-769X.2002.00078.x

[31] Svare H. Menn i pleie og omsorg: brødre i hvitt. Oslo: Universitetsforl.; 2009. 252.

[32] Vike H, Bakken R, Brinchmann A, Haukelien H, Kroken R. Maktens samvittighet: om politikk, styring og dilemmaer i velferdsstaten. Oslo: Gyldendal akademisk; 2002. 240.

[33] Ousey K, Johnson M. Being a real nurse - Concepts of caring and culture in the clinical areas. Nurse Education in Practice. 2007; 7(3): 150-5. PMID:17689438 http://dx.doi.org/10.1016/j .nepr.2006.06.001

[34] Rhodes MK, Morris AH, Lazenby RB. Nursing at its Best: Competent and Caring. Online Journal of Issues in Nursing. 2011; 16(2): 15-20.

[35] Suikkala A, Leino-Kilpi H. Nursing student-patient relationship: a review of the literature from 1984 to 1998. Journal of Advanced Nursing. 2001; 33(1): 42-50. http://dx.doi.org/10.1046/j.1 365-2648.2001.01636.x

[36] Newton JM, Billett S, Ockerby CM. Journeying through clinical placements - An examination of six student cases. Nurse Education Today. 2009; 29(6): 630-4. PMID:19231041 http://dx.doi .org/10.1016/j.nedt.2009.01.009 